\title{
A Rare and Massive Primitive Neuroectodermal Tumour
}

\section{Poornima Sivakumar*, Mohd Shahbaaz Khan, Biswajeet Mahapatra and Prasanta Das}

Department of Cardiothoracic and Vascular Surgery, SSKM Hospital, Kolkata, India

\section{Introduction}

Primitive neuroectodermal tumours was originally described by Askin et al. [1]. It is commonly found in children and young females. It frequently appears as a chest wall mass and grows rapidly to involve the neighboring pleura. The histogenesis of this rare tumour is uncertain and it is believed to be arising from the intercostal nerves. It exclusively arises from one hemi thorax and progresses rapidly to involve the chest wall. Involvement of the mediastinum in the adult is extremely rare in the literature and till now only five such cases in a span of twenty years have been reported from a tertiary care centre of India ${ }^{2]}$. We herein report the sixth case of an anterior mediastinal PNET in an adult female which had progressed rapidly to a huge mass involving the entire left hemithorax and measuring the heaviest PNET reported so far in the literature, (Table 1).

\section{Case Report}

A 63-year-old female, cook by profession from Kolkata, India presented with dry cough and progressive shortness of breath, left-sided severe chest pain, loss of weight and low-grade fever for 2 months. The patient was a non-smoker, non-alcoholic and non-diabetic. There was no history of similar illness in the family. General examination revealed pallor and there was no clubbing or peripheral lymphadenopathy.

On examination of the respiratory system features of left hemi thoracic volume enlargement were present and mediastinum was grossly shifted to the contralateral side. Percussion note was dull over the left hemithorax. On auscultation, a tubular breath sound was heard near the left infraclavicular area and vesicular breath sound was markedly diminished.

Chest X-ray postero-anterior view revealed left-sided homogenous opacity involving all three zones with loss of costophrenic and cardio phrenic angles along with contralaterally shifted mediastinum

\begin{tabular}{|c|c|c|}
\hline 1 & Kalkan et al. [9] & $3 \mathrm{~cm} \times 9 \mathrm{~cm}$ \\
\hline 2 & Younus et al. [10] & $10 \mathrm{~cm} \times 10 \mathrm{~cm}$ \\
\hline 3 & Najam and Vakili [11] & $2.5 \mathrm{~cm}$ \\
\hline 4 & Kahn et al. [12] & $4 \mathrm{~cm} \times 3 \mathrm{~cm} \times 3 \mathrm{~cm}$ \\
\hline
\end{tabular}

Table 1: Reference for large PNET reported so far in literature.

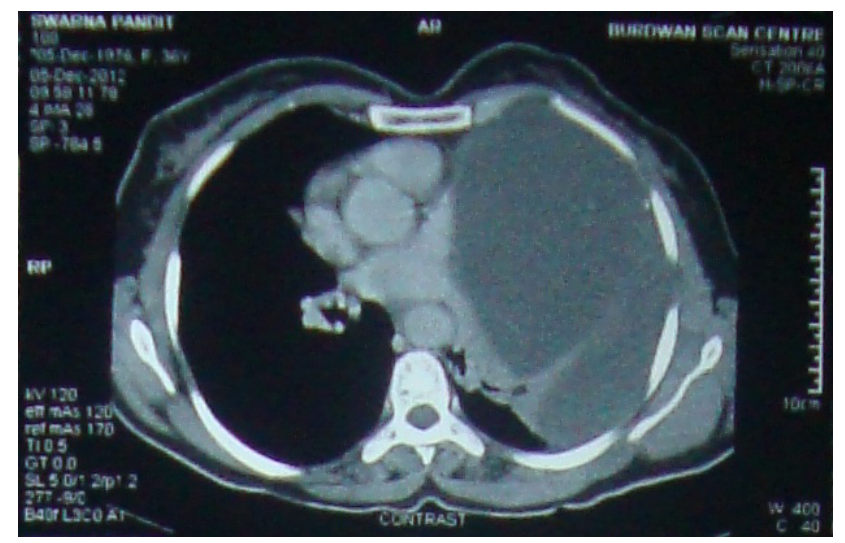

Figure 1: Contrast-enhanced CT. suggesting left-sided massive pleural effusion; but on thoracentesis, only $20 \mathrm{ml}$ hemorrhagic fluid could be aspirated from the left infrascapular area. Pleural fluid study yielded brownish-colored, predominantly lymphocytic, exudative fluid with high Adenosine De-aminase (ADA) [Total cell count- 190/cmm, lymphocyte- 90\%, neutrophil-5\%, ADA$143 \mathrm{IU}$, protein-4.2 g/dl). No acid-fast bacillus was found in sputum smear microscopy. Contrast-enhanced CT (CECT) scan showed a huge non-homogenous mass of heterogeneous density occupying the entire left hemi thorax, possibly arising from the anterior mediastinum, causing mediastinal shift to the right (Figure 1). CT-guided Fine Needle Aspiration Cytology (FNAC) suggested it to be a small roundcell tumour (PNET). Fibreoptic bronchoscopy showed no intraluminal growth. A diagnosis of PNET arising from the anterior mediastinum was made, a rare entity.

Patient was planned for surgery after the routine blood investigations which did not reveal any abnormalities. Patient was put on right lateral decubitus position with left hemithorax up and a left posterolateral thoracotomy was done. Left hemi thorax was opened through the fifth intercostal space. There was a huge $25 \times 15 \mathrm{cms}$ mass occupying the whole of the left hemithorax which was firm to hard in consistency with minimal adhesions to the surrounding pleura. The heart and trachea were pushed to the right. After releasing the adhesions and dissecting it from the neighboring structures the tumour was removed en bloc. The tumour was very heavy and it weighed 9.2 kilograms, the heaviest PNET tumour reported so far in the literature (Figure 2). The tumour was sent for pathological examination (Figure 3). The left lung expanded

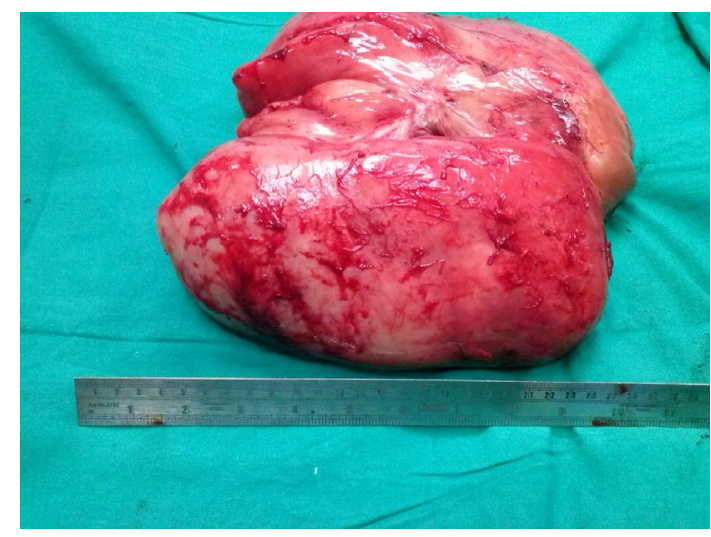

Figure 2: PNET tumour.

*Corresponding author: Poornima Sivakumar, Department of Cardiothoracic and Vascular Surgery, SSKM Hospital, Kolkata, India, E-mail: poornima.sivakumar@gmail.com

Received August 10, 2013; Accepted November 25, 2013; Published January 05, 2014

Citation: Sivakumar P, Khan MS, Mahapatra B, Das P (2014) A Rare and Massive Primitive Neuroectodermal Tumour. Surgery Curr Res 4: 159. doi:10.4172/21611076.1000159

Copyright: (c) 2014 Sivakumar P, et al. This is an open-access article distributed under the terms of the Creative Commons Attribution License, which permits unrestricted use, distribution, and reproduction in any medium, provided the original author and source are credited. 


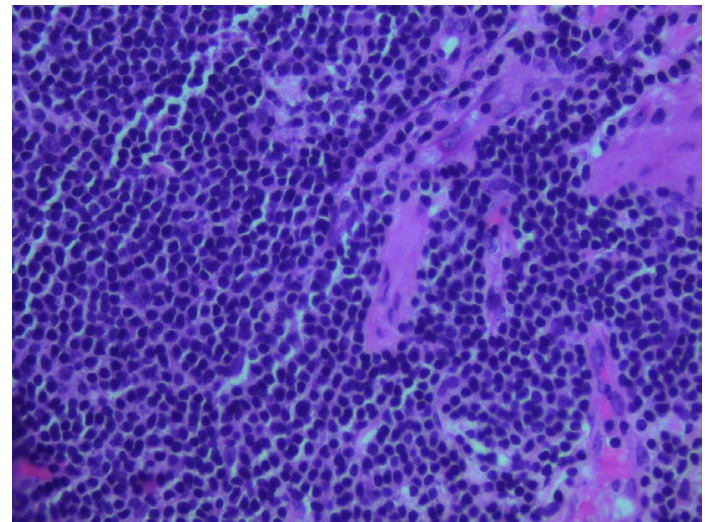

Figure 3: Pathological examination

well once the massive tumour was removed en bloc. The post-operative period was uneventful and the patient was discharged after 1 week. The pathology report revealed a small round cell tumour, PNET with borderline malignancy. On immunohistochemistry of the histology block, tumour cells were immunopositive for MIC-2, Vimentin and CD99 and were immunonegative for cytokeratin, synaptophysin, chromoganin a, CD 20, CD 3, tdt, and the findings were consistent with Primitive Neuroectodermal Tumours (PNETs) (Figure 3). The patient was referred to an oncologist for further chemoradioation.

\section{Discussion}

In 1973, Hart and Earle first coined the term Primitive Neuroectodermal Tumour (PNET) [3], which is more common in children and in the posterior mediastinum [4]. CT scan of the thorax reveals an ill-defined, heterogeneous mass with necrotic foci within, calcification is usually absent. The classic histological pattern of PNET consists of solid sheets of small uniform "primitive" cells with round nuclei and scanty cytoplasm that lack significant differentiation. Treatment is multimodal: Surgery followed by chemoradiation. PNET'S are very aggressive tumours and the expected 5 year survival is less than 20\% [5]. Data from literature suggest a better local control rate when RT is administered after complete surgical resection instead to irradiation alone.

\section{Conclusion}

In our report we present an adult female with a $25 \times 15 \mathrm{cms}$ PNET tumor occupying the entire left hemithorax arising from the anterior mediastinum and occupying the entire left hemithorax and weighing 9.2 kilograms, the heaviest and the largest reported in literature so far. Although ES/PNET arising from mediastinum is extremely rare [6-8], it should be considered in the differential diagnosis of mass in the hemithorax in adult patients and may benefit from an aggressive multimodality treatment.

\section{References}

1. Askin FB, Rosai J, Sibley RK, Dehner LP, McAlister WH (1979) Malignant small cell tumor of the thoracopulmonary region in childhood: a distinctive clinicopathologic entity of uncertain histogenesis. Cancer 43: 2438-2451.

2. Dubashi B, Cyriac S, Tenali SG (2009) Clinicopathological analysis and outcome of primary mediastinal malignancies - A report of 91 cases from a single institute. Ann Thorac Med 4: 140-142.

3. Hart MN, Earle KM (1973) Primitive neuroectodermal tumors of the brain in children. Cancer 32: 890-897.

4. Saifuddin A, Robertson RJ, Smith SE (1991) The radiology of Askin tumours. Clin Radiol 43: 19-23.

5. Gladish GW, Sabloff BM, Munden RF, Truong MT, Erasmus JJ, et al. (2002) Primary thoracic sarcomas. Radiographics 22: 621-637.

6. Ahmad R, Mayol BR, Davis M, Rougraff BT (1999) Extraskeletal Ewing's sarcoma. Cancer 85: 725-731.

7. El Weshi A, Allam A, Ajarim D, Al Dayel F, Pant R, et al. (2010) Extraskeletal Ewing's sarcoma family of tumours in adults: analysis of 57 patients from a single institution. Clin Oncol (R Coll Radiol) 22: 374-381.

8. Rud NP, Reiman HM, Pritchard DJ, Frassica FJ, Smithson WA (1989) Extraosseous Ewing's sarcoma. A study of 42 cases. Cancer 64: 1548-1553.

9. Kalkan KE, Bilci A, Selcukbiricik F, Unver N, Yuksel M (2013) Thoracic primitive neuroectodermal tumor. A rare case \& review of literature. Case Rep Pulmonol 2013: 326871.

10. Younus R, Khan A, Syed S (2002) Giant Askin Tumor: a diagnosis and therapeutic Challenge. J Pak Med Assoc 52: 82-85.

11. Najm S, Vakili ST (2008) Lung primary primitive neuroectodermal tumor in an adult patient. Respiratory Medicine CME 1: 161-163.

12. Kahn AG, Avagnina A, Nazar J, Elsner B (2001) Primitive Neuroectodermal Tumor of the Lung. Arch Pathol Lab Med 125: 397-399. 